\title{
Setting Priorities to Inform Assessment of Care Homes' Readiness to Participate in Healthcare Innovation: A Systematic Mapping Review and Consensus Process
}

\author{
Frances Bunn ${ }^{1, *}{ }^{\mathbb{D}}$, Claire Goodman ${ }^{1, *}$, Kirsten Corazzini ${ }^{2}$, Rachel Sharpe ${ }^{1}$, \\ Melanie Handley ${ }^{1}{ }^{(}$, Jennifer Lynch ${ }^{1}{ }^{(\mathbb{D}}$, Julienne Meyer ${ }^{3}$, Tom Dening ${ }^{4}(\mathbb{D}$ and \\ Adam L Gordon ${ }^{5}$ (D)
}

1 Centre for Research in Public Health and Community Care, University of Hertfordshire, College Lane, Hatfield, Hertfordshire AL10 9AB, UK; R.sharpe3@herts.ac.uk (R.S.); M.j.handley@herts.ac.uk (M.H.); J.lynch5@herts.ac.uk (J.L.)

2 University of Maryland School of Nursing, Baltimore, MD 21201, USA; Kcorazzini@umaryland.edu

3 Care for Older People, City, University of London, London EC1V OHB, UK; j.meyer@city.ac.uk

4 Division of Psychiatry and Applied Psychology, University of Nottingham, Nottingham NG7 2TU, UK; tom.dening@nottingham.ac.uk

5 Division of Medical Sciences and Graduate Entry Medicine, University of Nottingham, Derby DE22 3NE, UK; Adam.gordon@nottingham.ac.uk

* Correspondence: f.bunn@herts.ac.uk (F.B.); c.goodman@herts.ac.uk (C.G.)

Received: 10 December 2019; Accepted: 31 January 2020; Published: 5 February 2020

check for updates

\begin{abstract}
Organisational context is known to impact on the successful implementation of healthcare initiatives in care homes. We undertook a systematic mapping review to examine whether researchers have considered organisational context when planning, conducting, and reporting the implementation of healthcare innovations in care homes. Review data were mapped against the Alberta Context Tool, which was designed to assess organizational context in care homes. The review included 56 papers. No studies involved a systematic assessment of organisational context prior to implementation, but many provided post hoc explanations of how organisational context affected the success or otherwise of the innovation. Factors identified to explain a lack of success included poor senior staff engagement, non-alignment with care home culture, limited staff capacity to engage, and low levels of participation from health professionals such as general practitioners (GPs). Thirty-five stakeholders participated in workshops to discuss findings and develop questions for assessing care home readiness to participate in innovations. Ten questions were developed to initiate conversations between innovators and care home staff to support research and implementation. This framework can help researchers initiate discussions about health-related innovation. This will begin to address the gap between implementation theory and practice.
\end{abstract}

Keywords: long-term care; organisational; context older people; care homes

\section{Introduction}

In England, there are almost three times as many care home places as there are beds in the acute hospital sector, and one in six people aged 85 or over are living permanently in a care home [1]. Care home residents have complex healthcare needs due to multiple comorbidities (including dementia) yet do not always have access to the healthcare services that they would have if they were living in their own home [2]. In the UK, most care homes do not have registered nursing staff on site [3]. 
There is a growing recognition of the need for care home specific evidence that informs and improves healthcare of older people in these settings [4,5]. How improvements to healthcare for residents in care homes are implemented depends on a range of factors, including institutional and sectoral priorities, leadership styles, communication patterns, staff interest, and the quality of pre-existing relationships between staff and visiting healthcare professionals [6-8]. Understanding from the outset how the organisational context and culture of a care home influences readiness to participate in change is important. It has the potential to shape how healthcare professionals and care home staff plan their work together and explain the variability of uptake of new initiatives across the sector.

Implementation science recognises that differences in context influence innovation and implementation [9]. Context is a broad concept, and multiple implementation frameworks have operationalised the individual, organisational, and environmental factors involved [10,11]. Despite the rapid growth in implementation science in the healthcare sector in general, there is limited knowledge regarding how context affects innovation and implementation in care homes [12,13]. This is especially relevant when implementation involves practitioners from different types of organisations (public and private, health, and social care), with overlapping but distinct priorities, beliefs, and values.

A Canadian programme of work (Alberta Context Tool@ (ACT)) has linked assessment of the organisational context of care with a care home's capacity to embed new ways of working and caring into its everyday practice $[14,15]$. This has been done by studying different elements of organisational context, such as leadership styles and communication patterns and their impact on implementation of innovative models of care [16]. The aim of our study was to draw on this work to explore in more detail how the organisational context of the care home, and its constituent elements, might shape care home capacity and readiness to engage alongside health services in innovative approaches to care delivery. We aimed to identify the extent to which researchers have considered organisational contextual factors when planning and reporting the implementation of healthcare interventions in care homes. Organisations involved in innovation in care homes might then use these results to measure and better understand their local care home organisational contexts before attempting to implement changes.

\section{Methods}

The study had two phases. Phase 1 was a systematic mapping review of care home research. A mapping review is based on the concept that published articles not only represent findings but indirectly represent activity related to the finding $[17,18]$ — in this case, the impact of organisational context on implementation. We used the domain headings of the Alberta Context Tool to assess whether care home studies reported any pre or post hoc consideration of the impact of organisational context on readiness to engage in healthcare innovations. Phase 2 consisted of two consensus workshops where findings were reviewed using nominal group technique and stakeholders identified possible questions that practitioners could use to assess care home readiness.

\subsection{Phase 1 Systematic Mapping of The Literature}

\subsubsection{Inclusion Criteria}

We included Randomised Controlled Trials (RCTs) and process evaluations in three main areas: telehealth (video consultation and remote monitoring); integrated working between care home staff and visiting healthcare professionals; and comprehensive assessment and care planning, for example by general practitioners (GPs). The reason for including these areas was that they had been selected by commissioners in the English National Health Service (NHS) as priorities for improving care home residents' contact with the healthcare system. This was part of a broader strategic plan for system-wide change in NHS England [19], where interventions were piloted in six geographically disparate health 
economies identified as 'Vanguard sites' (known as the New Care Model Vanguard sites for Enhanced Health in Care Homes) [20].

In addition, we included RCTs, process evaluations, and qualitative studies that had reported on how context had informed uptake and implementation but whose intervention differed from those three areas of care.

\subsubsection{Search Strategy}

We searched PubMed and CINAHL for records published between 2009 and July 2016. The search was updated in June 2018. The search strategy (see Table 1) involved broad terms based on those used in a previous mapping review of care home research [4]. Non RCTs, such as process evaluations and qualitative studies, were identified from personal knowledge and from lateral searches, such as citation and keyword searches on Google Scholar.

Table 1. Search terms for the mapping review.

\begin{tabular}{l}
\hline PubMed. \\
\hline "nursing home" OR "residential facilities" OR “homes for the aged" (MESH) OR nursing homes (TI/AB], care \\
home [TI/AB] OR residential care [TI/AB] \\
AND "randomised controlled trial" OR "randomized controlled trial" (MESH) \\
\hline CINAHL \\
\hline "nursing homes" OR "residential facilities" OR "skilled nursing facilities" \\
\hline
\end{tabular}

\subsubsection{Data Extraction and Analysis}

Search results were downloaded into bibliographic software, and duplicates were deleted. Two authors independently screened the first 20 titles and abstracts to check for agreement (R.S., C.R.). The data extracted included information on study aims/research questions, interventions (including how care home staff were involved), participants, setting, type and size of care home, country, and information applicable to organisational context. The focus of data extraction was on factors related to implementation rather than the effectiveness of the intervention. The data was extracted by one of the following authors (R.S., C.R., M.H.) with $20 \%$ checked by a second author (F.B.). Disagreements relating to inclusion or data extraction were resolved by discussion with a third author (C.G. or F.B.).

We mapped the extent to which studies reported on implementation factors outlined in the Alberta Context Tool [21]. The rationale for choosing this particular tool is that it focuses on constructs related to organisation, addresses context assessment in long-term care facilities similar to English care homes, has been used in long-term care research, and draws upon the theoretical work of the Promoting Action on Research Implementation in Health Services (PARIHS) framework [22]. The ACT includes eight dimensions that are comprised of 10 contextual concepts: (1) leadership, (2) culture, (3) evaluation, (4) social capital, (5) structural and electronic resources, (6) formal interactions, (7) informal interactions, (8) organisational slack—staffing, (9) organisational slack-space, and (10) organisational slack - time [14,15]. For the analysis, the data were mapped against the ACT framework to determine if the study assessed care home contextual factors in planning or conducting the study and/or reported on the potential impact of factors on the implementation of the intervention.

\subsection{Phase 2 Consensus Workshops}

In phase 2, we tested the findings of the review with key stakeholders working in sites that had received additional NHS funding to improve working between healthcare professionals and care homes [20]. We invited care home managers and frontline care home staff, care home researchers, NHS commissioners, and providers of services to care homes to consensus workshops in two areas in England (Nottingham and London). Invitations were sent via the leads for each Vanguard site. Care home staff and managers who responded were self-selecting and were recruited on the basis of 
their interest in the topic rather than their representativeness. However, to be eligible, participants had to have direct experience working with NHS services and care homes. Before attending the half-day workshop, participants were sent a briefing document outlining the background to the research and the aims of the meeting. To structure the discussion at each workshop and rank the importance of the findings, we used the nominal group technique. This is a process that promotes the generation of ideas and enables the participation of all group members. The process involves four stages: (1) the generation of ideas, (2) recording of ideas, (3) discussing of ideas, and (4) prioritising of ideas [23]. To begin with, review findings were presented using the ACT headings to structure the discussion, and participants were asked whether findings resonated with their experiences. Research team members and participants recorded group discussions on index cards and flipcharts. Initial discussions resulted in 21 characteristics likely to affect care home readiness to participate in NHS-led service improvements. Using the nominal group technique [23], participants ranked these in order of importance. Thirty-five participants attended the two workshops (Table 2). Findings from the two phases were synthesised by members of the team (C.G., F.B., R.S., J.L., A.G.), and the key themes or ideas were expressed as questions. These questions were developed by the researchers and were not tested further with participants.

Table 2. Workshop participants.

\begin{tabular}{ccc}
\hline Workshop & Participants & \\
& Care home manager & \\
& Care home representative & 3 \\
London workshop $\mathrm{n}=21+3$ & organisation/charity & 4 \\
facilitators & NHS physician/nurse/therapist working & 6 \\
& with care homes & 3 \\
& NHS manager/commissioner & 5 \\
& Care home researchers & \\
Nottingham $n=14$ & Care home manager & 1 \\
+2 facilitators & Care home representative & 3 \\
& organisation/charity & 4 \\
& NHS physician/nurse/therapist working & 4 \\
& with care homes & 2 \\
\hline Total participants & NHS commissioner/manager & 35 \\
\hline
\end{tabular}

\section{Results}

\subsection{Systematic Mapping}

Fifty-six papers from 48 studies met our inclusion criteria (Figure 1). These included 36 RCTs [24-59] and 20 process evaluations or qualitative explorations of implementation [60-79]. We found studies from 10 countries: the United Kingdom (13), the United States (11), Australia (8), the Netherlands (5), Norway (3), Belgium, New Zealand, Canada (all 2), China (1), and France (1). An overview of the types of interventions and the domains of the ACT covered can be seen in Table 3. For further details of individual studies, see Supplementary Materials S1. 


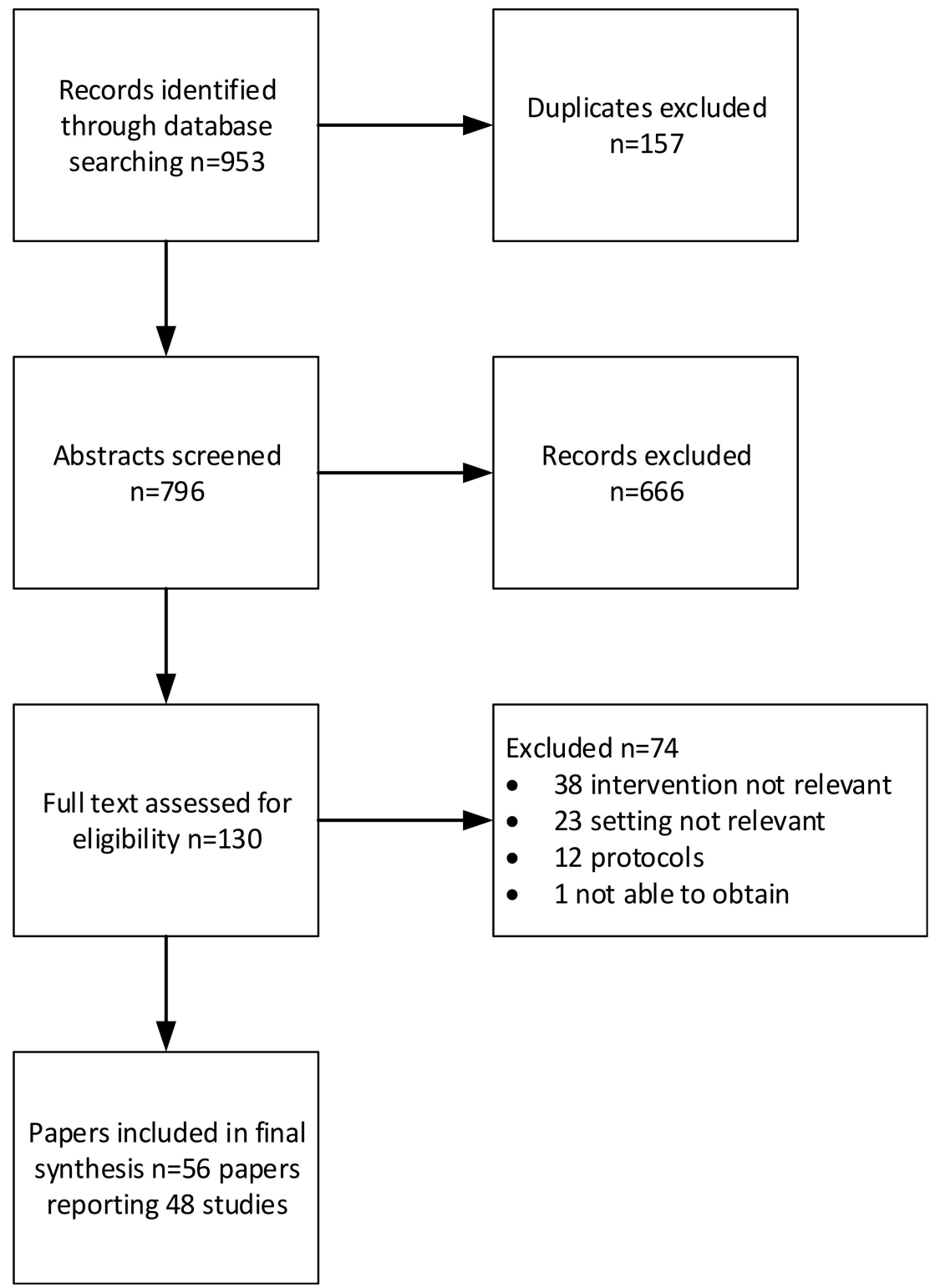

Figure 1. Selection of studies for inclusion in the mapping review. 
Table 3. Types of interventions and frequency with which Alberta Context Tool (ACT) domains were considered.

\begin{tabular}{|c|c|c|}
\hline Type of Intervention & $\mathrm{N}$ of Papers & Citations \\
\hline $\begin{array}{l}\text { Integrated working between care home staff } \\
\text { and visiting health professionals }\end{array}$ & 24 & $\begin{array}{l}{[24,25,27,28,32,35,36,38,39,42-45} \\
47,50,58,60,63-66,69,78,79]\end{array}$ \\
\hline $\begin{array}{c}\text { Comprehensive assessment and care } \\
\text { planning }\end{array}$ & 8 & {$[44-46,48-51,64-66,77]$} \\
\hline Telehealth & 3 & {$[31,33,41]$} \\
\hline $\begin{array}{l}\text { Other type of intervention (but provides } \\
\text { detail on organisational context) }\end{array}$ & 27 & $\begin{array}{c}{[26,28,32-35,38,39,44,47-49,54,58} \\
60-62,67,68,70-73,75]\end{array}$ \\
\hline Domain of ACT & Considered in paper $(n=)$ & Citations \\
\hline Leadership & 40 & $\begin{array}{c}{[24,25,27-31,34,36,38,40,42-50,52-} \\
56,58-60,62-64,66-69,72,73,75,77, \\
78]\end{array}$ \\
\hline Culture & 32 & $\begin{array}{c}{[24,27,34,36,37,42,45,46,48,49,52-} \\
55,58,59,62-64,66-70,72-76,78]\end{array}$ \\
\hline Evaluation & 12 & {$[25,39,40,44-46,48-51,64,66]$} \\
\hline Social capital & 13 & {$[25,31,49,59,64-66,68-70,72,76,77]$} \\
\hline Informal interactions & 11 & {$[30,49,55,57,59,60,64,65,67,72,77]$} \\
\hline Formal interactions & 30 & $\begin{array}{c}{[27-31,34,38,42,45,46,48-52,55,61} \\
\quad 63-66,68-70,72,73,76-79]\end{array}$ \\
\hline Structural/electronic resources & 22 & $\begin{array}{c}{[25,30,31,41,42,44-46,48-53,55,57,} \\
61,64-66,72,77]\end{array}$ \\
\hline Organisational slack—staff & 36 & $\begin{array}{c}{[24,26,27,29,30,34,36,38,42,45,47-} \\
50,52-54,56-61,63-68,73-78]\end{array}$ \\
\hline Organisational slack—space & 6 & {$[33,51,66,68,70,71]$} \\
\hline Organisational slack—time & 30 & $\begin{array}{c}{[24,27-30,34,37-39,45,47,49-53,55,} \\
56,58,59,61,65,66,68,70-73,77,78]\end{array}$ \\
\hline
\end{tabular}

None of the papers included a structured and comprehensive assessment of context that considered all the domains of the ACT. However, one study [48] used the PRECIS-2 tool [80] to evaluate implementation of their pragmatic randomised controlled trial, and another used the findings of an RCT in nursing homes to develop a tool to assess and manage the challenges facing complex organisational interventions [74]. However, the latter framework focuses on issues that arise during a study rather than anticipating and planning for them in the study design and set-up.

The most commonly considered areas of organisational context were leadership, culture, formal interactions, and staff availability. Where contextual assessment did feature, it was most frequently used as an unstructured post-hoc exploration of why an intervention had or had not worked. Detailed mapping of individual studies against the domains are shown in Tables S1 and S2.

\subsubsection{Leadership}

Most papers reviewed $(n=40)$ noted that care home leadership influenced the uptake of a given innovation. Studies cited the importance of leadership from care home managers and/or senior direct-care staff $[29,38,53,54,64,77]$ and from staff acting as clinical champions or persuasive leaders. Some studies attempted to address leadership issues prospectively through early engagement with care home managers $[30,34,36,38,45,66,77]$ and/or the appointment of clinical champions $[26,29,44,45,48-50,63,64]$. However, in many cases, engagement appeared superficial or limited. Examples where more sustained engagement was built into the trial design include the MARQUE study [45] and the WHELD study [44,64]. In the former, researchers held regular supervision and troubleshooting meetings with care home managers, and in the latter, champions were given sustained support and coaching aimed at building their confidence. This engagement process appeared to contribute to sustained delivery of the intervention.

A number of studies focused almost exclusively on the negative impact of a lack of leadership $[38,42,43,53,68,72,78]$. Issues cited included poor role clarity, managers' resistance to change, delegation of responsibilities to staff without the skill or authority to implement change, turnover of 
managers, and insufficient management attention to the innovation. Whilst these are well known to affect implementation, they had generally not been addressed as part of the innovation's development.

\subsubsection{Culture}

Positive cultural attributes were identified as those factors that gave time and resources to staff education, reinforcement of learning, and quality improvement $[43,45,52,54,64-67]$. Feedback on progress encouraged a sense of shared ownership of a given change [53]. Uptake was more likely when an intervention was acceptable to healthcare professionals, residents, and staff; when it fitted with existing care home routines; and when there were opportunities for ongoing consultation with staff $[36,45,60,69,70]$. Some studies attempted to proactively address the impact of culture, for example by involving stakeholders, such as care homes staff, in the development of the intervention [36,63,74].

Culture negatively affected uptake when the systems of care and required staffing levels were incompatible with those proposed by healthcare professionals or if care home staff felt that the proposed change implied a criticism of current practices [24,38,55,61]. Practices within the care home that specifically worked against the successful uptake of initiatives were the following: a task-focused approach to care, a preoccupation with risk reduction, or staff with a limited skill set working with residents who had advanced dementia $[34,37,62,68,71,73,75]$. Studies highlighted the importance of managerial support to change perceptions about what constituted real work. For example, supporting people so that they felt comfortable to sit and talk with residents rather than engaging in task-based care [49].

\subsubsection{Evaluation}

Care homes' use of data to assess performance and achieve outcomes was discussed in terms of staff's familiarity with gathering data and how they used information to inform quality improvement, specifically whether care homes easily provide information about residents' characteristics, document their participation and health-related outcomes, or provide information about relatives' involvement in care $[30,54,60,71-73,76]$. One study noted the related challenges of synthesising data from the multiple data sources within a care home [55]. Other studies described the benefits of engaging in pre-intervention work or adapting to current processes to ensure consistent documentation of care $[40,79]$.

\subsubsection{Social Capital}

Social capital recognises the existing resources and support networks, both formal and informal, available to a care home to deliver care. It helps to explain why care homes with similar populations may be more or less resilient and responsive to change. This domain was not explored in most of the research reviewed, although some studies reflected on how homes' connections, particularly with external services, affected implementation of care initiatives $[27,31,69,70,72,76]$. Specifically, absent or poor connections with general practitioners (community physicians), secondary care (hospitals), and professional or academic organisations were important in affecting how care homes worked with visiting healthcare practitioners. Two studies reported on the advantages of having clinicians working with care homes to support interventions to improve the quality of care $[25,36]$.

\subsubsection{Informal and Formal Interactions}

Low GP participation or resistance from GPs $[29,34,47,61,63,69,77-79,81]$, limited opportunities for formal communications in multidisciplinary team meetings $[27,28,60,72,73]$, and poor communication within the organisation $[55,68,73]$ were factors reported to be barriers to implementation. One study recognised the need in future work to address how group dynamics and peer pressure facilitates (or not) the adoption of the intervention and the possible benefits of preparatory coaching to build staff confidence in their practices [30]. Indeed, approaches that fostered a combination of formal and informal interactions, for example through regular meetings, coaching, interactive approaches, and 
good communication of information, were all identified as facilitators $[30,38,52,67,77]$. This included interactions between care home staff, between staff and external health professionals, and between staff and researchers.

\subsubsection{Structural/Electronic Resources}

Studies showed that when care homes experienced system changes or reorganisation, uptake of new interventions was limited [25]. Some studies did acknowledge the impact of this; for example, one study excluded care homes in which major innovation projects had recently been implemented [30]. Care home record keeping systems, and limited access to computers could have a negative impact on the collection of outcome data or participation in the study $[49,51,53,72]$. Some studies provided support or training to staff to improve recordkeeping or the use of IT in the care home $[48,64,66]$. In the WHELD study, recordkeeping for the research influenced the wider practice of the care home and led to an overall improvement in documentation [64]. This appeared to be because staff were actively engaged in the project and because the research enabled them to see the connection between care home practice and outcomes [64].

\subsubsection{Organisational Slack}

The biggest issue, identified by almost all studies $(n=43)$, was staff availability and capacity. This was expressed in four ways: staff workload, staff turnover, staff skills, and whether an innovation was seen as a priority by the care home. Some studies suggested that funding for staff time to deliver an intervention or attend training might ease the problem of staff availability $[29,42,45,53,63,68,75]$. Making time to build relationships, to agree how to work together, and to establish if the intervention was relevant to the care home was also important $[27,41,56,59,60,64]$. Space was less frequently mentioned as an issue, although two studies reported that the physical structure of the home could be challenging [68,71], for example making it difficult to maintain residents' privacy during research interviews [71].

\subsection{Consensus Workshops}

Participants at the consensus workshops recognised and validated the review findings. They found it challenging, however, to articulate how they would quantify these different aspects of care home context or assess how they affected readiness to participate, implement, and sustain innovation. For example, participants endorsed the importance of having enough time to get to know each other to build a shared agenda and mutually beneficial working relationships but were unsure how this is achieved or how many resources are required.

Similarly, everyone identified leadership approaches in the care home as key. They struggled, however, to unpack what type of leader was important, whether the level of managerial involvement was significant, or how staff turnover and availability might affect uptake of the interventions. Fewer still, despite personal experience in instituting healthcare change in and with care homes, had considered how the internal systems of the care home and surrounding networks of care affected uptake or whether the priorities of the NHS always aligned with those of the care homes.

Evidence showing that it was frequently difficult to engage healthcare professionals with different care home innovations resonated with participants at both workshops. Participants also noted that there was little information on what was required to ensure that visiting healthcare professionals were ready to work with care homes and limited evidence about how healthcare practitioners' prior knowledge and experience of working in care homes affected implementation. They observed that studies seldom considered if an innovation was wanted or needed by the care home and that they usually failed to partner with care home staff in planning innovation from the outset.

Workshop discussions identified 21 characteristics likely to affect care home readiness. When asked to rank them, participants identified the following as most important: having a capable and 
confident manager, alignment of priorities and staff buy-in, engagement with a care quality vision, evidence of a culture of change, and receptiveness of manager and senior staff to engage in change.

The findings were then developed by the research team into a series of questions (Table 4). These questions were designed to provide a framework to promote conversations between researchers, practitioners, and commissioners when considering innovation in care homes.

Table 4. Set of questions combining review findings with the workshop priorities.

\begin{tabular}{cl}
\hline 1 & \multicolumn{1}{c}{ Set of Questions Combining Review Findings with the Workshop Priorities } \\
\hline 2 & $\begin{array}{l}\text { Does this intervention align with care home priorities? } \\
\text { organisational and unit level? Are they willing and able to take an ongoing leadership role in } \\
\text { supporting the proposed change? }\end{array}$ \\
\hline 3 & $\begin{array}{l}\text { Do care home staff have enough 'slack and flexibility' to accommodate the change into their } \\
\text { current workload? Will it be recognised as core to their work? }\end{array}$ \\
\hline 5 & $\begin{array}{l}\text { How is change discussed (formally and informally) in the care home setting? Who needs to be } \\
\text { involved in decision-making about what is being proposed and how it is implemented? }\end{array}$ \\
\hline 6 & $\begin{array}{l}\text { What are the recent changes or health-related projects this care home has been involved with? } \\
\text { facilitate change? }\end{array}$ \\
\hline 7 & $\begin{array}{l}\text { What are the pre-existing relationships between NHS services and care home staff and networks } \\
\text { of care and support around the care home (e.g., general practitioners (GPs), visiting specialists, } \\
\text { links with local hospital)? }\end{array}$ \\
\hline 10 & $\begin{array}{l}\text { Could the intervention appear judgmental by signalling in a negative way that the care home } \\
\text { needs to change? }\end{array}$ \\
\hline How well do existing care home training programmes and work schedules fit with what \\
is proposed?
\end{tabular}

\section{Discussion}

To identify and map the contextual influences that affect successful implementation of healthcare interventions in care homes, we conducted a review of 56 care home papers and undertook workshops involving 35 participants. Both the review and the workshops offered evidence of how context influenced implementation but less knowledge of how to achieve context 'readiness'. The most commonly cited components of organisational context were leadership, care home culture, formal interactions, and organisational slack. The review demonstrated that researchers are aware of how context affects uptake of healthcare innovation in care home settings. Despite this, organisational context was generally used to explain problems with implementation post hoc, rather than being planned pre hoc as part of the study design.

Leadership, care home culture, and staff capacity to engage in and prioritise innovations are well recognised as important influences on uptake of innovation [82,83]. Given this, it is disappointing that, in many studies, these well-documented challenges are presented as findings, rather than being used to inform the study design. Overall, there were little data on what is required prior to innovation in terms of research design, involvement of staff, and the resources required. More recent trials in care homes $[44,45]$ have provided accounts of how care home context was addressed in setting up the study and delivering the intervention. For example, the WHELD study highlighted the importance of understanding the experiences of care home staff, engaging them as active members of the research team, and supporting them to develop skills and take ownership of the intervention [64,65].

A clear message from the workshops, and from the review, was that it takes time to develop relationships that support effective collaborations between visiting healthcare professionals and care 
homes. These findings are supported by a recent realist evaluation of health service delivery to care home residents in the English NHS [84]. This study found that service integration between the NHS and care homes was dependent on time, and support from commissioners to develop relational working. It is also suggested that a long preparatory period, consultation with a range of frontline staff and care home residents [83], and co-design of interventions could improve implementation [85].

Very few studies provided the opportunity for care home staff to comment on the relevance of research or the experience of participation. Further, residents' and relatives' voices are also largely missing from this study. This is, in part, because they were absent in the papers reviewed. It is a significant limitation that so little can be said about how residents and their representatives influence the planning and uptake of healthcare interventions.

\section{Limitations}

It is possible that the time limits incorporated in our search strategy meant that we missed relevant studies on care home context. In addition, we did not include study protocols, which might have provided more information about researchers' plans to address organisational context. Previous mapping reviews of trials conducted in care homes have not, however, revealed significant volumes of implementation literature in the sector that would have been likely to change our findings [4]. The ACT framework provided a useful tool for mapping organisational context. However, we found some overlaps between domains, for example organisational slack around staff and time. We conducted only two workshops with self-selected participants; thus, the consensus rankings need further refinement and testing with a wider audience.

\section{Conclusions}

Care home context and readiness for change is an important factor for the successful implementation of healthcare initiatives. Approaches to measuring context, such as the ACT, have been applied to individual research studies. Drawing on the findings of this article, there is a clear case to persevere with structural assessment of care home context in research. This requires a systematic approach to assessment at the beginning of an innovation or intervention. This synthesis and stakeholder engagement led to the development of questions that can be used to help researchers, practitioners, and commissioners begin conversations about the measures needed to bring care homes to a state of readiness for successful implementation of healthcare initiatives. Ultimately, asking these questions consistently across diverse care home settings will inform the development of a shared, core set of context assessment tools to support healthcare interventions in care homes in England and elsewhere.

Supplementary Materials: The following are available online at http://www.mdpi.com/1660-4601/17/3/987/s1, Table S1: Table of included studies, Table S2: Summary of the ACT domains and linked evidence from the mapping review.

Author Contributions: C.G., F.B., K.C., A.L.G., T.D., and J.M. conceived of the study and developed the protocol. CG led the study. R.S., M.H., F.B., C.G., and J.L. extracted data and participated in the synthesis process. C.G., R.S., A.L.G., and J.L. conducted the stakeholder groups. All the authors were involved in interpretation of the results. F.B., C.G., and J.M. wrote the paper. All the authors critically reviewed the paper. All authors have read and agreed to the published version of the manuscript.

Funding: This project was funded by a small grant from NHS England. The views expressed are those of the authors and not necessarily those of the NHS or the Department of Health and Social Care.

Acknowledgments: We would like to thank Charlotte Russell who assisted with screening and data extraction for the review.

Conflicts of Interest: The authors declare no conflicts of interest. 


\section{References}

1. Lee, S.K.; Posthauer, M.E.; Dorner, B.; Redovian, V.; Maloney, M.J. Pressure Ulcer Healing with a Concentrated, Fortified, Collagen Protein Hydrolysate Supplement: A randomized Controlled Trial. Adv Ski Wound Care. 2006, 19, 92-96. [CrossRef] [PubMed]

2. Iliffe, S.; Davies, S.L.; Gordon, A.L.; Schneider, J.; Dening, T.; Bowman, C.; Gage, H.; Martin, F.C.; Gladman, J.R.; Victor, C.; et al. Provision of NHS generalist and specialist services to care homes in England: Review of surveys. Prim. Health Care Res. Dev. 2016, 17, 122-137. [CrossRef] [PubMed]

3. CQC. The State of Adult Social Care Services 2014 to Findings from CQC's Initial Programme of Comprehensive Inspections in Adult Social Care. 2017. Available online: https://www.cqc.org.uk/sites/ default/files/20170703_ASC_end_of_programme_FINAL2.pdf (accessed on 28 August 2019).

4. Gordon, A.; Logan, P.; Jones, R.; Forrester-Paton, C.; Mamo, J.; Gladman, J.; Medical Crises in Older People Study Group. A systematic mapping review of Randomized Controlled Trials (RCTs) in care homes. BMC Geriatr. 2012, 12, 31. [CrossRef] [PubMed]

5. Morley, J.E.; Caplan, G.; Cesari, M.; Dong, B.; Flaherty, J.H.; Grossberg, G.T.; Holmerova, I.; Katz, P.R.; Koopmans, R.; Little, M.O.; et al. International Survey of Nursing Home Research Priorities. J. Am. Med. Dir Assoc. 2014, 15, 309-312. [CrossRef]

6. Goodman, C.; Dening, T.; Gordon, A.L.; Davies, S.L.; Meyer, J.; Martin, F.C.; Gladman, J.R.; Bowman, C.; Victor, C.; Handley, M.; et al. Effective health care for older people living and dying in care homes: A realist review. BMC Health Serv Res. 2016, 16, 269. [CrossRef]

7. Ko, M.; Wagner, L.; Spetz, J. Nursing Home Implementation of Health Information Technology: Review of the Literature Finds Inadequate Investment in Preparation, Infrastructure, and Training. Inquiry 2018, 55, 46958018778902. [CrossRef]

8. Vlaeyen, E.; Stas, J.; Leysens, G.; Van der Elst, E.; Janssens, E.; Dejaeger, E.; Dobbels, F.; Milisen, K. Implementation of fall prevention in residential care facilities: A systematic review of barriers and facilitators. Int. J. Nurs. Stud. 2017, 70, 110-121. [CrossRef]

9. Greenhalgh, T.; Robert, G.; Macfarlane, F.; Bate, P.K.O. Diffusion of innovations in service organizations: Systematic review and recommendationso Title. Milbank Q. 2004, 82, 581-629. [CrossRef]

10. Benzer, J.K.; Charns, M.P.; Hamdan, S.; Afable, M. The role of organizational structure in readiness for change: A conceptual integration. Health Serv. Manag. Res. 2017, 30, 34-46. [CrossRef]

11. Shortell, S.M. Increasing value: A research agenda for addressing the managerial and organizational challenges facing health care delivery in the United States. Med. Care Res. Rev. 2004, 61 (Suppl. 3), 12-30. [CrossRef]

12. Cammer, A.; Morgan, D.; Stewart, N.; McGilton, K.; Rycroft-Malone, J.; Dopson, S.; Estabrooks, C. The Hidden Complexity of Long-Term Care: How Context Mediates Knowledge Translation and Use of Best Practices. Gerontologist 2014, 54, 1013-1023. [CrossRef] [PubMed]

13. McConnell, E.S.; Corazzini, K.N.; Lekan, D.; Bailey, D.C.; Sloane, R.; Landerman, L.R.; Champagne, M.T. Diffusion of Innovation in Long-Term Care (DOI-LTC) Measurement Battery. Res. Gerontol. Nurs. 2012, 5, 64-76. [CrossRef] [PubMed]

14. Estabrooks, C.A.; Squires, J.E.; Cummings, G.G.; Birdsell, J.M.; Norton, P.G. Development and assessment of the Alberta Context Tool. BMC Health Serv. Res. 2009, 9, 234. [CrossRef] [PubMed]

15. Estabrooks, C.A.; Squires, J.E.; Hayduk, L.A.; Cummings, G.G.; Norton, P.G. Advancing the argument for validity of the Alberta Context Tool with healthcare aides in residential long-term care. BMC Med. Res. Methodol. 2011, 11, 107. [CrossRef]

16. Estabrooks, C.A.; Hoben, M.; Poss, J.W.; Chamberlain, S.A.; Thompson, G.N.; Silvius, J.L.; Norton, P.G. Dying in a nursing home: Treatable symptom burden and its link to modifiable features of work context. J. Am. Med. Dir. Assoc. 2015, 16, 515-520. [CrossRef]

17. Hanson, L.C.; Carey, T.S.; Caprio, A.J.; Lee, T.J.; Ersek, M.; Garrett, J.; Jackman, A.; Gilliam, R.; Wessell, K.; Mitchell, S.L. Improving Decision-Making for Feeding Options in Advanced Dementia: A Randomized, Controlled Trial. J. Am. Geriatr. Soc. 2011, 59, 2009-2016. [CrossRef]

18. Cooper, I.D. What is a "mapping study?". J. Med. Libr. Assoc. 2016, 104, 76-78. [CrossRef]

19. NHS England. Five Year Forward View. Available online: http://www.england.nhs.uk/wp-content/uploads/ 2014/10/5yfv-web.pdf (accessed on 28 August 2019). 
20. NHS England. New Care Model: Vanguards-Developing a Blueprint for the Future of NHS and Care Services. Available online: https://www.england.nhs.uk/wp-content/uploads/2015/11/new_care_models.pdf (accessed on 15 March 2016).

21. Squires, J.; Hayduk, L.; Hutchinson, A.; Mallick, R.; Norton, P.; Cummings, G.; Carole, A. Reliability and validity of the Alberta context tool (ACT) with professional nurses: Findings from a multi-study analysis. PLoS ONE 2015, 10, E0127405. [CrossRef]

22. Rycroft-Malone, J. The PARIHS framework-A framework for guiding the implementation of evidence-based practice. J. Nurs. Care Qual. 2004, 19, 297-304. [CrossRef]

23. Bartunek, J.; Murninghan, J. The nominal group technique: Expanding the basic procedure and underlying assumptions. Group Organ. Manag. 1984, 9, 417-432. [CrossRef]

24. Arendts, G.; Deans, P.; Brien, K.O.; Etherton-beer, C.; Howard, K.; Lewin, G.; Sim, M. A clinical trial of nurse practitioner care in residential aged care facilities. Arch. Gerontol. Geriatr. 2018, 77, 129-132. [CrossRef] [PubMed]

25. Boorsma, M.; Frijters, D.H.; Knol, D.L.; Ribbe, M.E.; Nijpels, G.; van Hout, H.P. Effects of multidisciplinary integrated care on quality of care in residential care facilities for elderly people: A cluster randomized trial. Cmaj 2011, 183, E724-E732. [CrossRef] [PubMed]

26. Colon-Emeric, C.S.; Mcconnell, E.; Pinheiro, S.O.; Corazzini, K.; Porter, K.; Earp, K.M.; Landerman, L.; Beales, J.; Lipscomb, J.; Hancock, K.; et al. CONNECT for Better Fall Prevention in Nursing Homes: Results from a Pilot Intervention Study. J. Am. Geriatr. Soc. 2014, 61, 2150-2159. [CrossRef] [PubMed]

27. Connolly, M.J.; Boyd, M.; Broad, J.B.; Kerse, N.; Lumley, T.; Whitehead, N.; Foster, S. The Aged Residential Care Healthcare Utilization Study (ARCHUS): A Multidisciplinary, Cluster Randomized Controlled Trial Designed to Reduce Acute Avoidable Hospitalizations From Long-Term Care Facilities. J. Am. Med. Dir. Assoc. 2015, 16, 49-55. [CrossRef]

28. Crotty, M.; Halbert, J.; Rowett, D.; Giles, L.; Birks, R.; Williams, H.; Whitehead, C. An Outreach Geriatric Medication Advisory Service in Residential Aged Care: A Randomised Controlled Trial of Case Conferencing. Age Ageing 2004, 33, 612-617. [CrossRef] [PubMed]

29. Davison, T.E.; Karantzas, G.; Mellor, D.; McCabe, M.P.; Mrkic, D. Staff-focused interventions to increase referrals for depression in aged care facilities: A cluster randomized controlled trial. Aging Ment. Health 2013, 17, 449-455. [CrossRef]

30. De Visschere, L.; Schols, J.; van der Putten, G.J.; de Baat, C.; Vanobbergen, J. Effect evaluation of a supervised versus non-supervised implementation of an oral health care guideline in nursing homes: A cluster randomised controlled clinical trial. Gerodontology 2012, 29, e96-e106. [CrossRef]

31. Dorsey, E.R.; Deuel, L.M.; Voss, T.S.; Finnigan, K.; George, B.P.; Eason, S.; Miller, D.; Reminick, J.I.; Appler, A.; Polanowicz, J.; et al. Increasing access to specialty care: A pilot, randomized controlled trial of telemedicine for Parkinson's disease. Mov. Disord. 2010, 25, 1652-1659. [CrossRef]

32. Dozeman, E.; Marwijk, H.W.J.; Van Schaik, D.J.F.; Van Smit, F.; Stek, M.L.; Horst, E.V.D.; Bohlmeijer, E.T.; Beekman, A.T. Contradictory effects for prevention of depression and anxiety in residents in homes for the elderly: A pragmatic randomized controlled trial. Int. Psychogeriatr. 2012, 24, 1242-1251. [CrossRef]

33. Field, T.S.; Tjia, J.; Mazor, K.M.; Donovan, J.L.; Kanaan, A.O.; Harrold, L.R.; Reed, G.; Doherty, P.; Spenard, A.; Gurwitz, J.H. Randomized trial of a warfarin communication protocol for nursing homes: An SBAR-based approach. Am. J. Med. 2011, 124, 179. [CrossRef]

34. Kinley Stone, L.; Dewey, M.; Levy, J.; Stewart, R.; McCrone, P.; Sykes, N.; Hansford, P.; Begum, A.; Hockley, J. The effect of using high facilitation when implementing the Gold Standards Framework in Care Homes programme: A cluster randomised controlled trial. Palliat. Med. 2014, 28, 1099-1109. [CrossRef]

35. McSweeney, K.; Jeffreys, A.; Griffith, J.; Plakiotis, C.; Kharsas, R.; O'Connor, D.W. Specialist mental health consultation for depression in Australian aged care residents with dementia: A cluster randomized trial. Int. J. Geriatr. Psychiatry 2012, 27, 1163-1171. [CrossRef]

36. Boyd, M.; Armstrong, D.; Parker, J.; Pilcher, C.; Zhou, L.; McKenzie-Green, B.; Connolly, M.J. Do gerontology nurse specialists make a difference in hospitalization of long-term care residents? Results of a randomized comparison trial. J. Am. Geriatr. Soc. 2014, 62, 1962-1967. [CrossRef]

37. Meeks, S.; Van Haitsma, K.; Schoenbachler, B.; Looney, S.W. BE-ACTIV for depression in nursing homes: Primary outcomes of a randomized clinical trial. J. Gerontol. B Psychol. Sci. Soc. Sci. 2015, 70, 13-23. [CrossRef] 
38. Rantz, M.; Zwygart-Stauffacher, M.; Hicks, L.; Mehr, D.; Flesner, M.; Petrovski, G.F.; Madsen, R.W.; Scott-Cawiezell, J. Randomized Multilevel Intervention to Improve Outcomes of Residents in Nursing Homes in Need of Improvement. J. Am. Med. Dir. Assoc. 2012, 4, 60-68. [CrossRef] [PubMed]

39. Underwood, M.; Lamb, S.E.; Eldridge, S.; Sheehan, B.; Slowther, A.M.; Spencer, A.; Thorogood, M.; Atherton, N.; Bremner, S.A.; Devine, A.; et al. Exercise for depression in elderly residents of care homes: A cluster-randomised controlled trial. Lancet 2013, 382, 41-49. [CrossRef]

40. Van der Kooij, C.H.; Droes, R.M.; de Lange, J.; Ettema, T.P.; Cools, H.J.; van Tilburg, W. The implementation of integrated emotion-oriented care: Did it actually change the attitude, skills and time spent of trained caregivers? Dement 2013, 12, 536-550. [CrossRef] [PubMed]

41. Vowden, K.; Vowden, P. A pilot study on the potential of remote support to enhance wound care for nursing-home patients. J. Wound Care 2013, 22, 481-488. [CrossRef] [PubMed]

42. Wenborn, J.; Challis, D.; Head, J.; Miranda-Castillo, C.; Popham, C.; Thakur, R.; Illes, J.; Orrell, M. Providing activity for people with dementia in care homes: A cluster randomised controlled trial. Int. J. Geriatr. Psychiatry 2013, 28, 1296-1304. [CrossRef] [PubMed]

43. Agar, M.; Luckett, T.; Luscombe, G.; Phillips, J.; Beattie, E.; Pond, D.; Mitchell, G.; Davidson, P.M.; Cook, J.; Brooks, D.; et al. Effects of facilitated family case conferencing for advanced dementia: A cluster randomised clinical trial. PLoS ONE 2017, 12, e0181020. [CrossRef] [PubMed]

44. Ballard, C.; Orrell, M.; Sun, Y.; Moniz-Cook, E.; Stafford, J.; Whitaker, R.; Woods, B.; Corbett, A.; Banerjee, S.; Testad, I.; et al. Impact of antipsychotic review and non-pharmacological intervention on health-related quality of life in people with dementia living in care homes: WHELD—a factorial cluster randomised controlled trial. Int. J. Geriatr. Psychiatry 2017, 32, 1094-1103. [CrossRef] [PubMed]

45. Livingston, G.; Barber, J.; Marston, L.; Stringer, A.; Panca, M.; Hunter, R.; Cooper, C.; Laybourne, A.; La Frenais, F.; Reeves, S.; et al. Clinical and cost-effectiveness of the Managing Agitation and Raising Quality of Life (MARQUE) intervention for agitation in people with dementia in care homes: A single-blind, cluster-randomised controlled trial. Lancet Psychiatry 2019, 6, 293-304. [CrossRef]

46. Overbeek, A.; Korfage, I.J.; Jabbarian, L.J.; Billekens, P.; Hammes, B.J.; Polinder, S.; Severijnen, J.; Swart, S.J.; Witkamp, F.E.; van der Heide, A.; et al. Advance Care Planning in Frail Older Adults: A Cluster Randomized Controlled Trial. J. Am. Geriatr. Soc. 2018, 66, 1089-1095. [CrossRef] [PubMed]

47. Beer, C.; Horner, B.; Flicker, L.; Scherer, S.; Lautenschlager, N.T.; Bretland, N.; Flett, P.; Schaper, F.; Almeida, O.P. A cluster-randomised trial of staff education to improve the quality of life of people with dementia living in residential care: The DIRECT study. PLoS ONE 2011, 6, e28155. [CrossRef] [PubMed]

48. Palmer, J.A.; Mor, V.; Volandes, A.E.; McCreedy, E.; Loomer, L.; Carter, P.; Dvorchak, F.; Mitchell, S.L. A dynamic application of PRECIS-2 to evaluate implementation in a pragmatic, cluster randomized clinical trial in two nursing home systems. Trials 2018, 19, 453. [CrossRef] [PubMed]

49. Surr, C.A.; Holloway, I.; Walwyn, R.E.A.; Griffiths, A.W.; Meads, D.; Kelley, R.; Martin, A.; McLellan, V.; Ballard, C.; Fossey, J.; et al. Dementia Care Mapping TM to reduce agitation in care home residents with dementia: The DCM ${ }^{\mathrm{TM}}$ EPIC cluster randomised controlled trial. Health Technol. Assess. 2019, 2019, 1-239.

50. Husebo, B.S.; Ballard, C.; Aarsland, D.; Selbaek, G.; Slettebo, D.D.; Gulla, C.; Aasmul, I.; Habiger, T.; Elvegaard, T.; Testad, I.; et al. The Effect of a Multicomponent Intervention on Quality of Life in Residents of Nursing Homes: A Randomized Controlled Trial (COSMOS). J. Am. Med. Dir. Assoc. 2019, 20, 330-339. [CrossRef]

51. Brazil, K.; Carter, G.; Cardwell, C.; Clarke, M.; Hudson, P.; Froggatt, K.; McLaughlin, D.; Passmore, P.; Kernohan, W.G. Effectiveness of advance care planning with family carers in dementia nursing homes: A paired cluster randomized controlled trial. Palliat. Med. 2018, 32, 603-612. [CrossRef]

52. Beeckman, D.; Clays, E.; Hecke, A.; Vanderwee, K.; Schoonhoven, L.; Verhaeghe, S. A multi-faceted tailored strategy to implement an electronic clinical decision support system for pressure ulcer prevention in nursing homes: A two-armed randomized controlled trial. Int. J. Nurs. Stud. 2013, 50, 475-486. [CrossRef]

53. Blekken, L.E.; Nakrem, S.; Gjeilo, K.H.; Norton, C.; Morkved, S.; Vinsnes, A.G. Feasibility, acceptability, and adherence of two educational programs for care staff concerning nursing home patients' fecal incontinence: A pilot study preceding a cluster-randomized controlled trial. Implement. Sci. 2015, 10, 72. [CrossRef]

54. Brodaty, H.; Low, L.F.; Liu, Z.; Fletcher, J.; Roast, J.; Goodenough, B.; Chenoweth, L. Successful ingredients in the SMILE study: Resident, staff, and management factors influence the effects of humor therapy in residential aged care. Am. J. Geriatr. Psychiatry 2014, 22, 1427-1437. [CrossRef] [PubMed] 
55. Brooker, D.J.; Latham, I.; Evans, S.C.; Jacobson, N.; Perry, W.; Bray, J.; Ballard, C.; Fossey, J.; Pickett, J. FITS into practice: Translating research into practice in reducing the use of anti-psychotic medication for people with dementia living in care homes. Aging Ment. Health 2015, 7863, 1-10. [CrossRef] [PubMed]

56. Chami, K.; Gavazzi, G.; Bar-Hen, A.; Carrat, F.; de Wazières, B.; Lejeune, B.; Armand, N.; Rainfray, M.; Hajjar, J.; Piette, F.; et al. A Short-Term, Multicomponent Infection Control Program in Nursing Homes: A Cluster Randomized Controlled Trial. J. Am. Med. Dir. Assoc. 2012, 13, 569. [CrossRef] [PubMed]

57. Chi, I.; Law, B.V.; Leung, A.C.; Liu, C.P.; Yeoh, C.S.; Cheng, Y.H.; Ma, A.M.; Kwan, C.K.; Lai, C. Residential Assessment Instrument 2.0 in care planning for residents in nursing homes. Hong Kong Med. J. 2010, 16 (Suppl. 3), 29-33. [PubMed]

58. Stern, A.; Mitsakakis, N.; Paulden, M.; Alibhai, S.; Wong, J.; Tomlinson, G.; Brooker, A.S.; Krahn, M.; Zwarenstein, M. Pressure ulcer multidisciplinary teams via telemedicine: A pragmatic cluster randomized stepped wedge trial in long term care. BMC Health Serv. Res. 2014, 14, 83. [CrossRef] [PubMed]

59. Anderson, K.; Bird, M.; Macpherson, S.; McDonough, V.; Davis, T. Findings from a pilot investigation of the effectiveness of a snoezelen room in residential care: Should we be engaging with our residents more? Geriatr. Nurs. 2011, 32, 166-177. [CrossRef]

60. Close, H.; Hancock, H.; Mason, J.M.; Murphy, J.J.; Fuat, A.; de Belder, M.; Hungin, A.P. “It's Somebody else's responsibility"-Perceptions of general practitioners, heart failure nurses, care home staff, and residents towards heart failure diagnosis and management for older people in long-term care: A qualitative interview study. BMC Geriatr. 2013, 13, 69. [CrossRef]

61. Cohen-Mansfield, J.; Thein, K.; Marx, M.S.; Dakheel-Ali, M. What are the barriers to performing nonpharmalogical interventions for Behavioral symptoms in the nursing home? J. Am. Med. Dir. Assoc. 2012, 100, 130-134.

62. Stein-Parbury, J.; Chenoweth, L.; Jeon, Y.H.; Brodaty, H.; Haas, M.; Norman, R. Implementing Person-Centered Care in Residential Dementia Care. Clin. Gerontol. 2012, 35, 404-424. [CrossRef]

63. Beer, C.; Lowry, R.; Horner, B.; Almeida, O.P.; Scherer, S.; Lautenschlager, N.T.; Bretland, N.; Flett, P.; Schaper, F.; Flicker, L. Development and evaluation of an educational intervention for general practitioners and staff caring for people with dementia living in residential facilities. Int. Psychogeriatr. 2011, 23, 221-229. [CrossRef]

64. Fossey, J.; Garrod, L.; Tolbol Froiland, C.; Ballard, C.; Lawrence, V.; Testad, I. What influences the sustainability of an effective psychosocial intervention for people with dementia living in care homes? A 9 to 12-month follow-up of the perceptions of staff in care homes involved in the WHELD randomised controlled trail. Int. J. Geriatr. Psychiatry 2019, 34, 674-682. [CrossRef] [PubMed]

65. Fossey, J.; Garrod, L.; Lawrence, V.; Testad, I.; Stafford, J.; Murray, J. “We should see her like part of the team": An investigation into care home staff's experiences of being part of an RCT of a complex psychosocial intervention. Aging Ment. Health 2018, 2018, 1-8. [CrossRef] [PubMed]

66. Fossey, J.; Garrod, L.; Guzman, A.; Testad, I. A qualitative analysis of trainer/coach experiences of changing care home practice in the Well-being and Health in Dementia randomised control trial. Dementia 2018, 19, 237-252. [CrossRef] [PubMed]

67. Colon-Emeric, C.S.; Pinheiro, S.O.; Anderson, R.A.; Porter, K.; McConnell, E.; Corazzini, K.; Hancock, K.; Lipscomb, J.; Beales, J.; Simpson, K.M. Connecting the learners: Improving uptake of a nursing home educational program by focusing on staff interactions. Gerontologist 2014, 54, 446-459. [CrossRef] [PubMed]

68. Ellard, D.R.; Thorogood, M.; Underwood, M.; Seale, C.; Taylor, S.J. Whole home exercise intervention for depression in older care home residents (the OPERA study): A process evaluation. BMC Med. 2014, $12,1$. [CrossRef] [PubMed]

69. Gage, H.; Dickinson, A.; Victor, C.; Williams, P.; Cheynel, J.; Davies, S.L.; Iliffe, S.; Froggatt, K.; Martin, W.; Goodman, C. Integrated working between residential care homes and primary care: A survey of care homes in England. BMC Geriatr. 2012, 12, 71. [CrossRef] [PubMed]

70. Greenspan, S.L.; Nace, M.D.; Perera, S.F.M.; Ferchak, M.; Fiorito, G.; Medich, D.; Zukowski, K.; Adams, D.; Lee, C.; Saul, M. Lessons Learned from an Osteoporosis Clinical Trial in Frail Long Term Care Residents. Clin. Trials 2012, 100, 130-134. [CrossRef]

71. Hall, S.; Longhurst, S.; Higginson, I.J. Challenges to conducting research with older people living in nursing homes. BMC Geriatr. 2009, 9, 38. [CrossRef] 
72. Innis, J.; Berta, W. Routines for change: How managers can use absorptive capacity to adopt and implement evidence-based practice. J. Nurs. Manag. 2016. [CrossRef]

73. Oye, C.; Mekki, T.E.; Jacobsen, F.F.; Førland, O. Facilitating change from a distance-A story of success? A discussion on leaders' styles in facilitating change in four nursing homes in Norway. J. Nurs. Manag. 2016, 24, 745-754. [CrossRef]

74. Simpson, K.M.; Porter, K.; McConnell, E.S.; Colon-Emeric, C.; Daily, K.A.; Stalzer, A.; Anderson, R.A. Tool for evaluating research implementation challenges: A sense-making protocol for addressing implementation challenges in complex research settings. Implement. Sci. 2013, 8, 2. [CrossRef] [PubMed]

75. Van Ness, P.H.; Peduzzi, P.N.; Quagliarello, V.J. Efficacy and effectiveness as aspects of cluster randomized trials with nursing home residents: Methodological insights from a pneumonia prevention trial. Contemp. Clin. Trials 2012, 33, 1124-1131. [CrossRef]

76. Shepherd, V.; Nuttall, J.; Hood, K.; Butler, C.C. Setting up a clinical trial in care homes: Challenges encountered and recommendations for future research practice. BMC Res. Notes 2015, 8, 306. [CrossRef] [PubMed]

77. Aasmul, I.; Husebo, B.S.; Flo, E. Description of an advance care planning intervention in nursing homes: Outcomes of the process evaluation. BMC Geriatr. 2018, 18, 26. [CrossRef] [PubMed]

78. Luckett, T.; Chenoweth, L.; Phillips, J.; Brooks, D.; Cook, J.; Mitchell, G.; Pond, D.; Davidson, P.M.; Beattie, E.; Luscombe, G.; et al. A facilitated approach to family case conferencing for people with advanced dementia living in nursing homes: Perceptions of palliative care planning coordinators and other health professionals in the IDEAL study. Int. Psychogeriatr. 2017, 29, 1713-1722. [CrossRef] [PubMed]

79. Poot, A.J.; de Waard, C.S.; Wind, A.W.; Caljouw, M.A.A.; Gussekloo, J. A Structured Process Description of a Pragmatic Implementation Project: Improving Integrated Care for Older Persons in Residential Care Homes. Inquiry 2017, 54, 0046958017737906. [CrossRef] [PubMed]

80. Loudon, K.; Treweek, S.; Sullivan, F.; Donnan, P.; Thorpe, K.E.; Zwarenstein, M. The PRECIS-2 tool: Designing trials that are fit for purpose. BMJ 2015, 350, h2147. [CrossRef] [PubMed]

81. Poot, A.J.; Caljouw, M.A.A.; Waard, C.S.; de Wind, A.W.; Gussekloo, J. Satisfaction in Older Persons and General Practitioners during the Implementation of Integrated Care. PLoS ONE 2016, 11, e0164536. [CrossRef]

82. Chaudoir, S.R.; Dugan, A.G.; Barr, C.H.I. Measuring factors affecting implementation of health innovations: A systematic review of structural, organizational, provider, patient, and innovation level measures. Implement. Sci. 2013, 8, 22. [CrossRef]

83. Marshall, M.; de Silva, D.; Cruickshank, L.; Shand, J.; Wei, L.; Anderson, J. What we know about designing an effective improvement intervention (but too often fail to put into practice). BMJ Qual. Saf. 2017, 26, 578-582. [CrossRef]

84. Goodman, C.; Davies, S.L.; Gordon, A.L.; Dening, T.; Gage, H.; Meyer, J.; Schneider, J.; Bell, B.; Jordan, J.; Martin, F.; et al. Optimal NHS service delivery to care homes: A realist evaluation of the features and mechanisms that support effective working for the continuing care of older people in residential settings. Health Serv. Deliv. Res. 2017, 5, 1-204. [CrossRef] [PubMed]

85. Marshall, M.; Pagel, C.; French, C.; Utley, M.; Allwood, D.; Fulop, N.; Pope, C.; Banks, V.; Goldmann, A. Moving improvement research closer to practice: The Researcher-in-Residence model. BMJ Qual. Saf. 2014, 23, 801-805. [CrossRef] [PubMed]

(C) 2020 by the authors. Licensee MDPI, Basel, Switzerland. This article is an open access article distributed under the terms and conditions of the Creative Commons Attribution (CC BY) license (http://creativecommons.org/licenses/by/4.0/). 